\title{
Análise da Flutuação do Nível D'água para Estimativa da Recarga Subterrânea da Bacia Representativa do Rio Gramame no Nordeste Brasileiro
}

\author{
Victor Hugo Rabelo Coelho; Cristiano das Neves Almeida; Alain Marie B. Passerat de Silans \\ Centro de Tecnologia/UFPB \\ victor-coelho@hotmail.com; almeida74br@yahoo.com.br; alainsilans@yahoo.com.br
}

Recebido: 01/08/11 - revisado: 25/12/11 - aceito: 10/01/12

\begin{abstract}
RESUMO
O monitoramento e o conhecimento da taxa de recarga de aqüiferos são necessários para uma gestão eficiente e sustentável das águas subterrâneas. Este trabalho apresenta os resultados da avaliação da taxa de recarga direta do aqǘfero livre da bacia representativa do rio Gramame (BRG), através da utilização do método WTF (Water Table Fluctuation). Para tanto, foi realizado o monitoramento quantitativo das águas subterrâneas em poços existentes na região e tratamento de dados de precipitação da bacia. Três comportamentos distintos foram detectados nas flutuações dos níveis dos poços, influenciados pela distribuição da precipitação, espessura da camada não saturada do solo e elevação do terreno. A recarga direta calculada para a BRG durante o ano hidrológico do monitoramento (2009/2010) foi de 73,8 mm, o que representa 7,2\% da precipitação média $(1026 \mathrm{~mm})$ na região para este ano hidrológico. Estes valores ficaram abaixo do esperado para uma região úmida, possivelmente pelo baixo indice pluviométrico registrado durante a pesquisa, que foi aproximadamente $42 \%$ menor do que a média anual da bacia. O baixo índice pluviométrico também influenciou na variação negativa do armazenamento subterrâneo $(\Delta S)$, que foi de $-105,9 \mathrm{~mm}$. O monitoramento sistemático do aqǘfero por um período mais longo é recomendado para dar subsídios na tomada de decisões quanto à utilização da água subterrânea da BRG.
\end{abstract}

Palavras-chave: água subterrânea; monitoramento; recarga direta; método WTF.

\section{INTRODUÇ̃̃O}

A preocupação com o gerenciamento dos recursos hídricos subterrâneos é crescente nos países em que esta fonte de abastecimento é bastante explorada, principalmente nas regiões áridas e semiáridas, que sofrem com a carência de água superficial. As estatísticas nacionais para o uso da água subterrânea são escassas, mas inúmeras publicações destacam a importância deste recurso. Na América Latina, muitas das maiores cidades do continente utilizam as águas subterrâneas no abastecimento municipal (WHO, 2006). Este fato é confirmado por CarreraHernández \& Gaskin (2007), eles afirmam que 70\% da Região Metropolitana da Cidade do México é abastecida por água subterrânea. Os números são ainda mais significativos nos países asiáticos e africanos (WHO, 2006). Na Índia, China, Tailândia, Indonésia e Vietnã, mais de $50 \%$ das fontes potáveis originam das águas subterrâneas. Na África, milhões de pessoas em áreas rurais e comunidades de baixa renda são dependentes de águas subterrâneas (WHO, 2006). Devido à importância desta fonte hídrica para a expansão urbana, agrícola e industrial de uma re- gião, o monitoramento e o conhecimento da taxa real da recarga do aqüífero são necessários para uma gestão eficiente e sustentável das águas subterrâneas (Vries \& Simmers, 2002; Banerjee et al., 2009).

Nas últimas décadas, mais precisamente a partir de 1980, muitos hidrólogos vêm tentando estimar a recarga natural de aqüíferos (Vries \& Simmers, 2002; Sanford, 2002). Desde então, vários métodos vêm sendo empregados para atingir esse objetivo. No entanto, vários fatores são determinantes para a escolha de um método adequado para cada região, sendo muitas vezes necessária a utilização de vários deles para realizar uma comparação entre os resultados (Vries \& Simmers, 2002; Scanlon et al., 2002; Healy \& Cook, 2002; Mazieiro, 2005; Coes et al., 2007). Para escolher um método adequado devem ser levados em consideração, além da influência de cada região, os objetivos a serem alcançados. Estes objetivos estão diretamente relacionados com o nível de exigência, no que se refere à precisão dos resultados, à dimensão do sistema envolvido e às características hidrogeológicas locais (Barreto, 2006; Wendland et al., 2007). Buscando sanar qualquer dúvida quanto à aplicação do método adequado para cada região, de acordo com os objetivos a serem alcançados, foram realizadas revisões destes métodos de 
estimativa de recarga por Lerner et al. (1990), Vries \& Simmers (2002), Sanford (2002), Scanlon et al. (2002), Barreto (2006), Rabelo (2006) e Gomes (2008).

Os métodos físicos estão entre os mais utilizados para estimar a taxa de recarga em aqüíferos livres, principalmente aqueles baseados na flutuação do nível d'água subterrâneo. Entre estas técnicas, destaca-se o método WTF (Water Table Fluctuation) como sendo o mais empregado. No Brasil, alguns trabalhos foram desenvolvidos aplicando esta metodologia, principalmente no Estado de São Paulo, com destaque para os de Wahnfried \& Hirata (2005), Rabelo (2006), Wendland et al. (2007), Mazieiro \& Wendland (2008), Carnier Neto \& Hung Kiang (2008) e Gomes (2008), todos com resultados satisfatórios.

Delin et al. (2006) aplicaram quatro métodos de estimativa de recarga para calibrar o modelo RRR (Recharge Regression Regional) em uma região semiúmida do Estado de Minnesota, nos Estados Unidos. Entre os métodos utilizados estava o WTF, considerado por eles como o método mais simples e fácil de ser aplicado, desde que os dados das flutuações estejam disponíveis. Os valores encontrados a partir deste método apresentaram boa convergência quando comparados com outros métodos utilizados. Apesar dos métodos baseados nas flutuações do nível freático serem mais apropriados para regiões de clima úmido e semi-úmido (Scanlon et al., 2002), esta técnica está sendo utilizada de maneira satisfatório em regiões de clima árido e semi-árido (Maréchal et al., 2006; Sharda et al., 2006; Sibanda et al., 2009).

Considerando este contexto, este artigo tem por objetivo determinar a taxa de recarga do aqüífero livre da bacia representativa do rio Gramame (BRG) e avaliar o seu comportamento, a partir da utilização da metodologia WTF. Para tanto, foi realizado o monitoramento do nível estático da água subterrânea em poços existentes na região e tratamento de dados de precipitação da bacia.

\section{MATERIAIS E MÉTODOS}

\section{Localização e Descrição da Área de Estudo}

A BRG está localizada na região litorânea do nordeste brasileiro, entre as coordenadas de $7^{0} 11^{\prime} \mathrm{e}$ $7^{0} 24^{\prime}$ de latitude sul e $34^{0} 48^{\prime}$ e $35^{0} 10^{\prime}$ de longitude oeste (Figura 1). Sua área aproximada de $590 \mathrm{~km}^{2}$ abrange vários municípios importantes do Estado da Paraíba, incluindo a capital João Pessoa e sua região metropolitana. A classificação climática de Köeppen indica um clima tropical chuvoso para a região, sem períodos frios e com chuva predominante de outonoinverno. A temperatura média anual é superior a $26^{\circ} \mathrm{C}$, com precipitações variando entre 1400 e 1800 $\mathrm{mm} /$ ano (PDRH, 2000).

\section{Geologia e Hidrogeologia Local}

A bacia do rio Gramame está inserida na Bacia Sedimentar Paraíba (BSP), que se limita ao sul pela Zona de Cisalhamento de Pernambuco (ZCPE), e ao norte pela falha de Mamamguape. Esta última representa uma ramificação da Zona de Cisalhamento de Patos (ZCPA) (Barbosa et al., 2007).

A BSP é subdividida em três sub-bacias, compartimentadas, respectivamente, no sentido norte-sul em: Miriri, Alhandra e Olinda. O aqüífero livre da bacia do rio Gramame, área de estudo deste trabalho, está contida, em sua totalidade, na Sub-Bacia Alhandra (SBA).

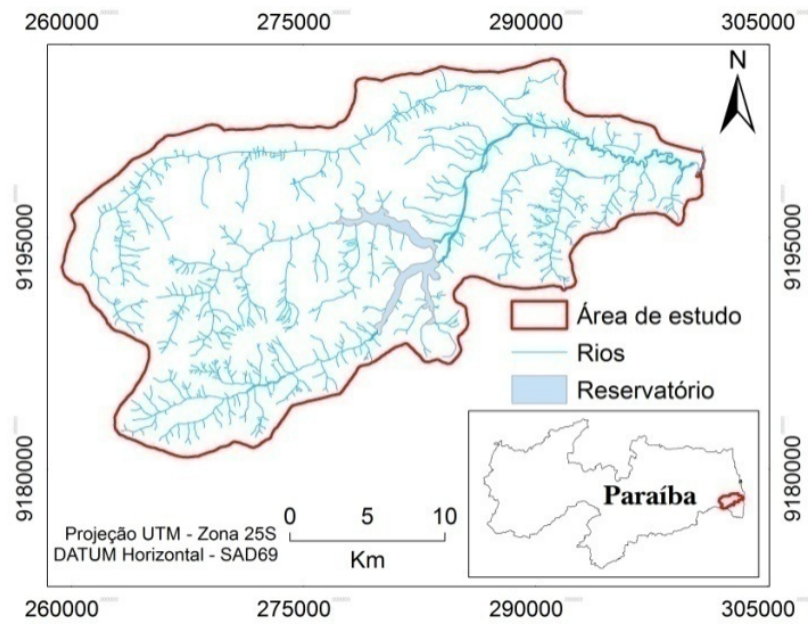

Figura 1 - Localização da área de estudo

Na SBA, Figura 2, se apresentam dispostas quatro unidades litoestratigráficas, depositadas em períodos geológicos distintos, como mencionaram Furrier et al. (2006). A unidade litoestratigráfica basal é denominada de Formação Beberibe, representada por um espesso pacote de arenitos com granulação variável e espessura média de 230 a $280 \mathrm{~m}$. Acima da Formação Beberibe repousa de forma concordante à Formação Gramame, de ambiente marinho raso, espessura média inferior a $55 \mathrm{~m}$ e predominância de calcários argilosos cinzentos. A continuação da seqüência calcária da Formação Gramame, diferenciada apenas pelo conteúdo fossilífero, cuja 
espessura máxima é de $30 \mathrm{~m}$, é denominada de Formação Maria Farinha. Recobrindo de forma discordante todas as rochas sedimentares da BSP descritas acima e o embasamento cristalino pré-cambriano, encontram-se os sedimentos areno-argilosos da Formação Barreiras (Furrier et al., 2006), onde os poços estudados estão inseridos.

Os sedimentos da Formação Barreiras, porção do aqüífero livre estudada, são provenientes do processo de intemperismo sobre o embasamento cristalino do Planalto da Borborema, e possuem espessura bastante variável no Estado da Paraíba, podendo atingir até $80 \mathrm{~m}$ (Alheiros et al., 1988). A Figura 2 mostra a seqüência litoestratigráfica da SBA. Aluviões e coberturas arenosas mais específicas também estão presentes na BRG.

A BSP faz parte da Província Hidrogeológica Costeira, que abrange extensa faixa litorânea do país. Os aqüíferos mais promissores e bem distribuídos da província, de acordo com Mente (2008), correspondem aos clásticos não consolidados e fracamente consolidados de idade cenozóica (TQb = Barreiras; Q = Aluviões, sedimentos flúviomarinhos e eólicos), presentes na BRG.

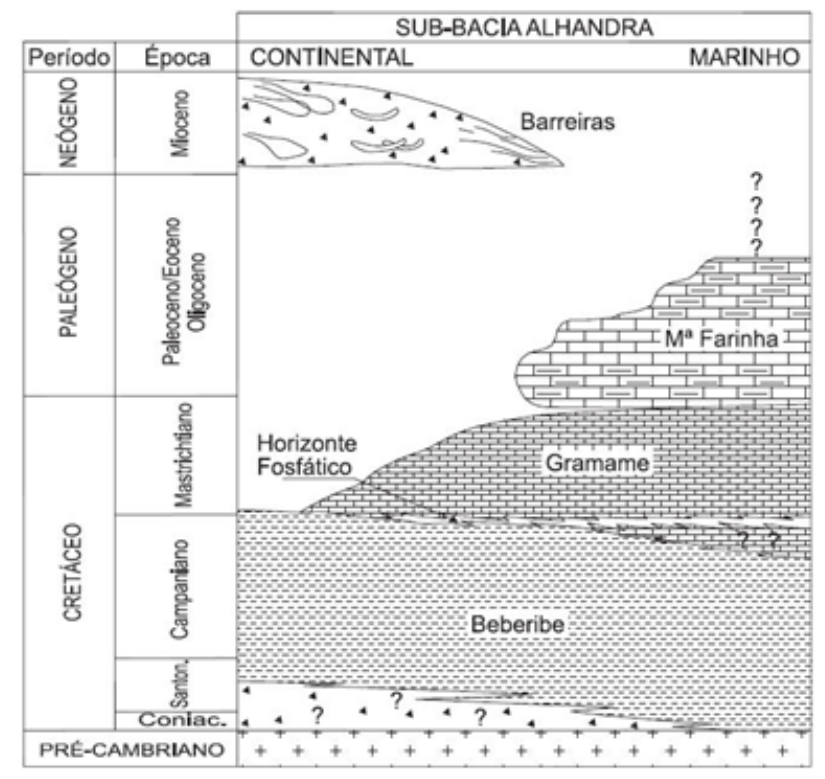

Figura 2 - Estratigrafia da Sub-Bacia Alhandra (Fonte: Furrier, 2006)

\section{Método WTF (Water Table Fluctuation)}

O método WTF foi utilizado para estimar a recarga natural direta do aqüífero livre da BRG. Esta técnica é bastante empregada para regiões de clima úmido, devido ao pequeno número de variáveis ne- cessário para sua aplicação. A estimativa pode ser realizada utilizando dados da flutuação dos níveis d'água subterrânea ao longo do tempo. Esta metodologia é baseada na premissa de que as elevações dos níveis d'água em aqüíferos não confinados são resultantes da água precipitada, que atinge a superfície livre através do processo de infiltração, caracterizando a recarga (Healy \& Cook, 2002; Scalon et al., 2002). A equação em que este método se baseia é dada por:

$R=S_{y} \frac{d h}{d t} \cong S_{y} \frac{\Delta h}{\Delta t}$

Onde $\mathrm{R}$ é a recarga estimada $(\mathrm{L} / \mathrm{T}), \mathrm{S}_{\mathrm{y}}$ é o coeficiente de rendimento específico do aqüífero (adimensional), h é a altura do nível d'água (L), e t é o tempo (T). O método WTF assume que todos os outros componentes do balanço hídrico (fluxo de base, entrada e saída subsuperficial e evapotranspiração) são nulos durante a recarga.

A aplicação da Equação 1 para cada elevação de nível d'água determina uma estimativa da recarga total, onde $\Delta \mathrm{h}$ é igual a diferença entre o pico de subida e o ponto mais baixo da curva de recessão antecedente extrapolada até o instante do pico. A curva de recessão antecedente extrapolada é a linha que a curva do poço teria na ausência de elevação de nível d'água (Healy \& Cook, 2002), como mostra a Figura 3

O desenho da linha é subjetivo e tenta adaptar a função de defasagem entre o início da precipitação e o início da recarga, como mencionou Barreto (2006). Gomes (2008) utilizou uma função do tipo exponencial para extrapolar as curvas de recessão dos níveis dos poços, entretanto, Healy \& Cook (2002) afirmaram não haver um tipo específico de função. Para este trabalho foi adotada a função potencial utilizada por Wendland et al. (2007):

$N_{c}=a \cdot\left(P-P_{0}\right)^{b}$

Onde Nc é o nível calculado; P o número de dias contados a partir do primeiro dia de monitoramento dos níveis; $\mathrm{a}$, b e $\mathrm{P}_{0}$ são parâmetros a serem determinados.

Com a identificação dos parâmetros da função de recessão do poço, aplica-se a função aos outros períodos de recessão, mantendo $a$ e $b$ próximos aos valores encontrados para a primeira curva de recessão do nível do aqüífero. A extrapolação da curva é feita até o ponto em que se inicia um novo período recessivo. Para a determinação dos parâmetros da função potencial foi utilizada a ferramenta Solver do Excel. Para tanto, buscou-se minimizar o 
somatório dos desvios entre os níveis calculados e observados.

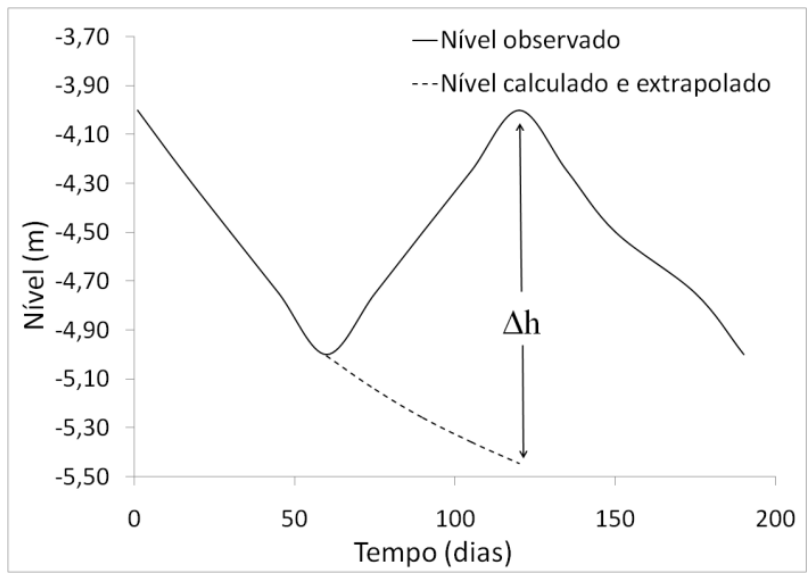

Figura 3 - Variação hipotética demonstrando a diferença da altura entre o pico de elevação da curva observada e a curva de recessão extrapolada

Este método pode ser utilizado para estimar a taxa de recarga em grandes áreas, desde que os níveis freáticos apresentem súbitas elevações e declínios de níveis d'água, o que é mais comum em aqüíferos rasos e regiões com elevados índices de precipitação. Quando o aqüífero não apresenta respostas às precipitações o método assume uma taxa de recarga nula.

\section{Variação do Armazenamento Subterrâneo}

A partir dos dados dos níveis dos poços de monitoramento e o conhecimento do rendimento específico do aqüífero, ambos utilizados para determinar a recarga natural direta através do método WTF, pode-se estimar a variação do armazenamento subterrâneo, que em aqüíferos livres corresponde à mudança do volume d'água que ocorre em relação a um nível anterior (Gomes, 2008), isto para período de tempo a ser considerado. Assim, a variação do armazenamento subterrâneo é dada por:

$\Delta S=\Delta h \cdot S_{y}$

Em que $\Delta \mathrm{S}$ é a variação do armazenamento subterrâneo $(\mathrm{L}) ; \Delta h$ é a variação da altura do nível d'água do aqüífero obtida a partir de poços de monitoramento (L); e $\mathrm{S}_{\mathrm{y}}$ é o coeficiente de rendimento específico do aqüífero (adimensional).

Como foi descrito nas Equações 1 e 3, a estimativa da recarga natural direta através da metodologia WTF e o conhecimento da variação do armaze- namento subterrâneo requerem, além dos dados de variação do níveis d'água, o conhecimento do rendimento específico do aqüífero, também denominado de porosidade útil.

O valor do coeficiente de rendimento específico da Formação Barreiras, descrito na literatura para o aqüífero livre da faixa costeira Pernambuco Rio Grande do Norte, varia entre 5 e $10 \%$, como apresentado nos trabalhos de Lucena et al., 2006; Costa et al., 2007; Silva et al., 2008; Melo et al., 2010 e Borba et al., 2010. Para este trabalho, foi adotado o valor de $7 \%$, que corresponde também à média do rendimento específico dos materiais com textura argilo-arenosa determinada por Johnson (1967).

\section{Monitoramento dos dados}

O monitoramento do nível estático do aqüífero livre foi realizado através de 27 poços existentes na região. Estes poços foram selecionados de forma a melhor representar o comportamento espacial da recarga e foram cadastrados com GPS Garmim (Gpsmap76csx). Os poços, localizados em sua maioria na zona rural, possuem profundidade variando entre 3,5 e $36 \mathrm{~m}$, com média de $11,5 \mathrm{~m}$. Os níveis estáticos, por sua vez, apresentaram variação entre 2,1 e 27,5 m, com média de 8,2 m.

Os dados de níveis estáticos foram adquiridos manualmente, através de um medidor de nível com dispositivo de contato elétrico, e correspondem ao período de um ano hidrológico (novembro de 2009 a outubro de 2010).

A freqüência de obtenção destes dados variou de acordo com a distribuição temporal da precipitação na região. No período de estiagem foi adotada uma freqüência mensal na coleta, que de acordo com Zhou (1996) é suficiente para determinar estudos de níveis d'água. Nos meses de maio, junho e julho, quando as precipitações são mais freqüentes e intensas na região, o intervalo da medição foi quinzenal, baseado no trabalho de Wendland et al. (2007). As coletas quinzenais foram realizadas com o objetivo de detectar as menores oscilações dos níveis provocadas pela percolação da água durante e após eventos chuvosos.

A análise dos dados de precipitação é bastante importante para identificar sua influência nas variações dos níveis, já que a precipitação é um dos principais fenômenos responsáveis pelo processo de recarga de aqüíferos livres (Moon et al., 2004). Para este estudo os dados de precipitação foram adquiridos através de nove estações pluviométricas inseridas na bacia e seu entorno, e são referentes ao período de monitoramento do nível do aqüífero. As poucas 
falhas foram corrigidas e homogeneizadas através do método do vetor regional. A precipitação média da bacia e a área de influência de cada posto pluviométrico foram determinadas através do método de Thiessen. A Figura 4 mostra a distribuição dos postos pluviométricos e dos poços monitorados na BRG.

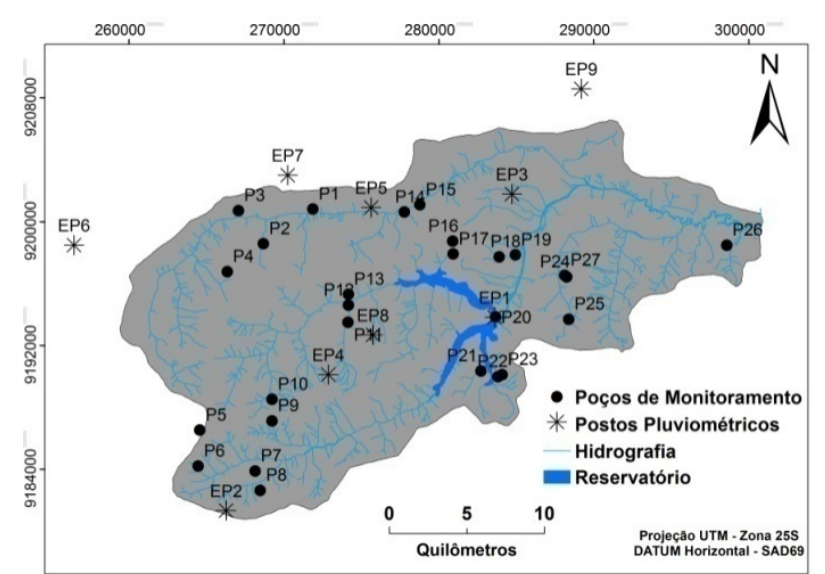

Figura 4 - Distribuição espacial dos postos pluviométricos e dos poços monitorados

\section{RESULTADOS E DISCUSSÃO}

\section{Análise da Precipitação}

A precipitação anual média na bacia para o período do monitoramento, obtida através das nove estações pluviométricas, foi de $1026 \mathrm{~mm}$. Este valor representa uma redução do índice pluviométrico de aproximadamente $42 \%$ quando comparado com o ano hidrológico anterior à pesquisa. A comparação mensal entre os dois períodos mostra que os meses de fevereiro, março, abril, maio, e principalmente julho, ficaram bem abaixo do normal.

A Figura 5 mostra as áreas de influência de cada posto pluviométrico na bacia, determinadas através dos polígonos de Thiessen, e seus respectivos valores anuais de chuva. Através dela, observa-se que os maiores índices pluviométricos estão concentrados na porção leste da bacia. Quase todas as estações exercem influência em pelo menos um dos poços monitorados, com exceção da estação pluviométrica 6 (EP 6), que não possui nenhum poço em sua área de influência.

\section{Análise das Variações dos Níveis Estáticos}

A maioria dos 27 poços, monitorados com freqüência mensal/quinzenal, é utilizada pela população local para o consumo humano e algumas ativi- dades domésticas, com pouca retirada de água. Alguns deles não estão sendo utilizados, como é o caso dos poços 6, 8, 10 e 11. Antes das visitas aos poços monitorados, os moradores eram comunicados, para que a retirada de água pudesse ser paralisada pelo menos 12 horas antes da medição do nível, como proposto por Feitosa \& Feitosa (2008). Os poços 3, 22 e 26 foram descartados do estudo, pois apresentaram influência do bombeamento durante algumas campanhas de campo.

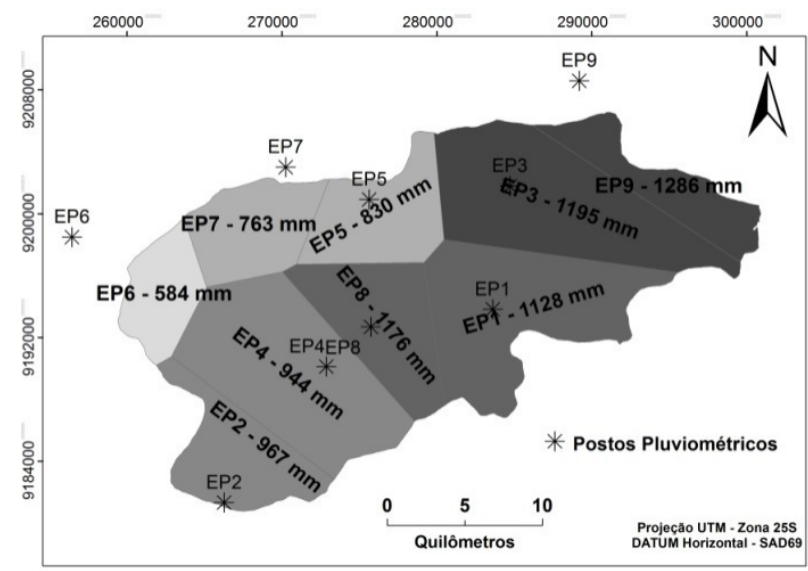

Figura 5 - Área de influência dos postos pluviométricos e precipitação anual por estação

O poço 2 também foi descartado das análises, pois apresentou comportamento fora dos padrões durante algumas visitas à campo, onde o nível do aqüífero chegou a subir quase 3 metros no intervalo de trinta dias. Este poço não está sendo utilizado pelos moradores locais, pois fazem referência ao alto teor de sais presente na água. Estudos mais detalhados serão realizados para saber o motivo das rápidas elevações do nível, que pode estar associado à interação do aqüífero livre com a camada de calcário da Formação Gramame ou a caminhos preferenciais.

Desta forma, 23 poços foram utilizados para análise das variações do nível estático do aqüífero, onde foram constatados três diferentes tipos de flutuação dos níveis nos poços.

\section{Tipo I}

A variação do Tipo I é a que apresentou constantes oscilações dos níveis durante o período estudado, com estes aumentando em resposta aos maiores eventos de precipitação na bacia. A maioria dos poços estudados apresentou este tipo de variação, doze no total. A Figura 6 mostra o comporta- 
Análise da Flutuação do Nível D”água para Estimativa de Recarga Subterrânea da Bacia Representativa do Rio Gramame no Nordeste Brasileiro

mento do nível do poço 20, com características de variação do Tipo I. De maneira geral, a ascensão dos níveis aconteceu durante os meses de fevereiro, junho, julho e agosto. O dia 1, representado nas figuras seguintes, corresponde ao primeiro dia do monitoramento $(10 / 11 / 2009)$.

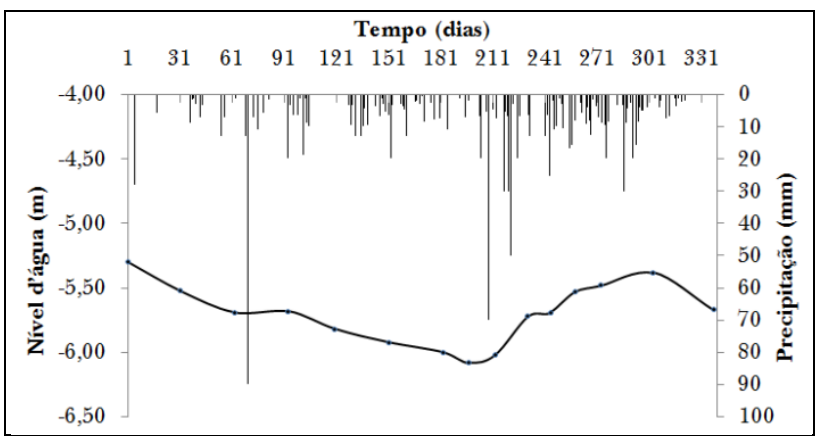

Figura 6 - Hidrograma subterrâneo do poço 20 com variação do Tipo I

Tipo II

A variação do Tipo II é representada pelos poços que apresentaram respostas lentas às precipitações. De maneira geral, apenas os eventos chuvosos dos meses de junho, julho e agosto atingiram a zona saturada do solo, provocando pequenas elevações dos níveis. A Figura 8 mostra a variação do nível do poço 6 , característico deste tipo de variação.

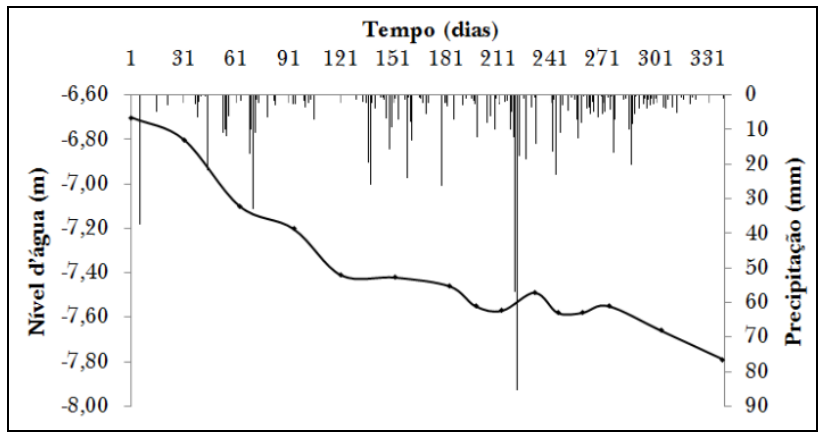

Figura 7 - Hidrograma subterrâneo do poço 6 com variação do Tipo II

Tipo III

As curvas do Tipo III não apresentaram respostas dos níveis aos eventos de precipitação, ou seja, sem nenhuma ascensão do nível em relação à medição anterior durante todo o monitoramento. Apenas
3 poços apresentaram esta tendência, exemplificada na Figura 8 para o poço 23.

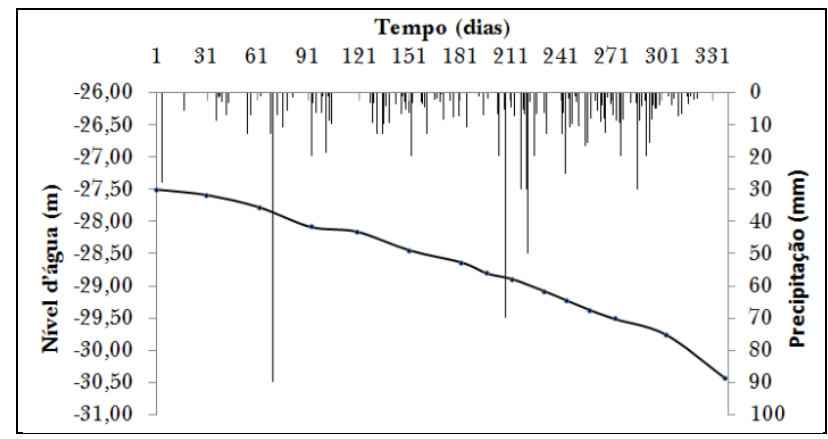

Figura 8 - Hidrograma subterrâneo do poço 23 com variação do Tipo III

Os fatores que influenciam no padrão de variação dos níveis dos poços podem estar associados a diferentes causas, e uma análise mais consistente destas deve ser realizada para o melhor conhecimento do aqüífero. Buscando encontrar as causas pelas quais ocorreram estes três tipos de variações durante o período de monitoramento, foram realizadas investigações de alguns fatores que podem influenciar na ocorrência dos 3 tipos de variações. Os fatores analisados foram: a precipitação, a topografia, o uso e ocupação do solo, a granulometria da camada superficial do solo, a geologia, a espessura da camada não saturada e condutividade hidráulica do solo.

A média da espessura da camada não saturada do solo dos poços com variação do Tipo I foi de 4,91 m, valores abaixo das variações dos Tipos II e III, cuja média da camada não saturada foi de $9 \mathrm{~m}$ e 21 $\mathrm{m}$, respectivamente. As Figuras 6, 7 e 8 ilustram este comportamento para os poços 20, 6 e 23, com a espessura da camada não saturada do solo aumentando à medida que se têm menores variações. A Figura 9 mostra a relação entre as condições de variação dos níveis dos poços e a topografia da bacia. O mapa topográfico com resolução de $90 \mathrm{~m}$, obtido através do modelo digital de elevação do SRTM (Shuttle Radar Topography Mission), mostra que as regiões mais baixas, representadas na maioria das vezes pelos aluviões, apresentam o maior número de poços enquadrados na condição de variação do Tipo I. Grande parte dos poços que exibiram variação do Tipo II está localizada nas regiões de elevação intermediária. Nas regiões com altitudes mais elevadas encontram-se os poços mais profundos, que não apresentaram recarga. 
A Figura 10 mostra as isoietas na bacia, obtidas através do método do inverso da distância ao quadrado, a partir das informações dos postos pluviométricos utilizados. Com as informações das condições de variação sobrepostas, pode-se notar uma maior concentração de poços que apresentaram variação do Tipo I na região onde a chuva foi maior. $\mathrm{Na}$ região de maior concentração das precipitações está inserido apenas o poço 23, o mais profundo dentre os monitorados e que apresentou variação do Tipo III. Nas regiões mais claras do mapa, onde as chuvas foram menores, apenas quatro poços apresentaram respostas rápidas.

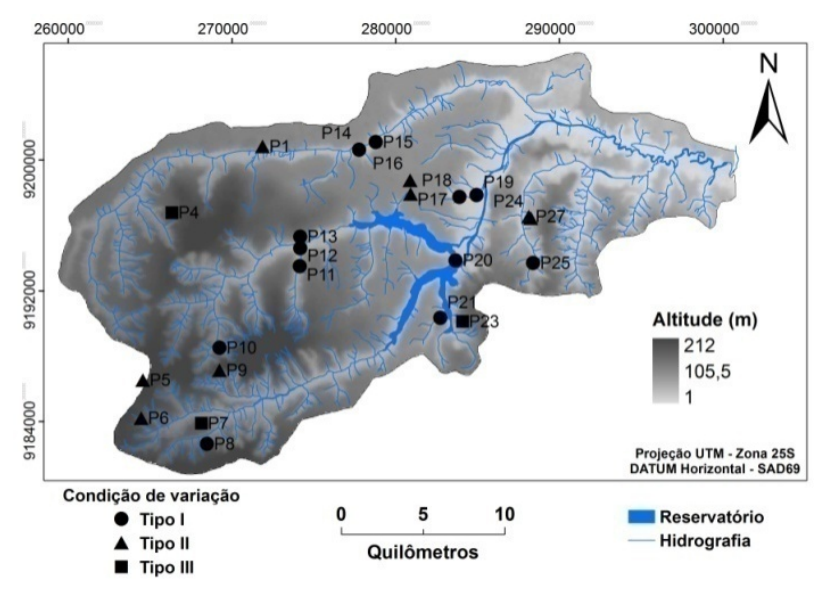

Figura 9 - Elevação do terreno da bacia e distribuição espacial das condições de variação dos níveis dos poços

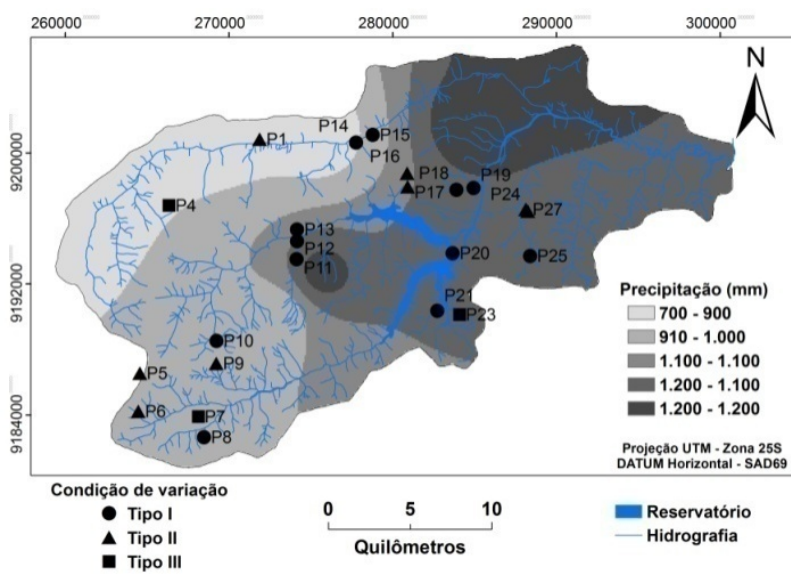

Figura 10 - Isoietas na bacia e distribuição espacial das condições de variação dos níveis dos poços
Os três tipos de variações dos níveis dos poços foram mais influenciados pela espessura da camada não saturada do solo, topografia e precipitação. Os outros fatores exerceram pouca ou nenhuma influência, portanto não foram apresentados.

\section{Recarga Natural Direta}

A recarga natural direta foi estimada através do método WTF para o ano hidrológico 2009/2010. A Figura 11 mostra as extrapolações das curvas de recessão do poço 25, necessárias para a aplicação da metodologia. Como apresentou várias elevações do nível após períodos recessivos, por estar enquadrado no Tipo I de variação, várias extrapolações foram realizadas.

Os poços do Tipo III, que apresentaram apenas rebaixamento do nível, foram descartados para a aplicação do método WTF, pois como não houve elevação do lençol freático a recarga estimada pelo método seria nula. $O$ poço 1 também não foi utilizado, pois a elevação do nível d'água foi mínima. Os poços com influência de bombeamento e o poço 7 , que já haviam sido descartados para a análise dos níveis, também foram desprezados para a estimativa de recarga. Com isso, foi estimada a recarga direta de 19 poços monitorados. As curvas dos demais poços podem ser encontradas em Coelho (2011).

A Tabela 1 mostra a precipitação anual, a espessura da camada não saturada do solo, o somatório da altura entre as curvas extrapoladas e observadas, a taxa de recarga e a porcentagem da recarga em relação à precipitação para os 19 poços considerados neste estudo.

O poço 12 foi que apresentou a maior taxa de recarga, superando os $190 \mathrm{~mm}$, o que corresponde a $16,2 \%$ da precipitação registrada na estação EP8, com área de influência neste poço, durante o período de estudo. A Tabela 2 mostra a recarga direta mensal do poço 12 e seus respectivos valores de precipitação. Neste poço as recargas aconteceram nos meses de fevereiro, maio, junho, julho e agosto, com as maiores precipitações nos meses de janeiro, abril, junho, julho e agosto. As recargas registradas para os meses de fevereiro e maio, onde as precipitações não foram as mais elevadas, são remanescentes dos meses de janeiro e abril, já que neste período a freqüência do monitoramento foi mensal. Este detalhe foi observado para todos os poços do Tipo I, que apresentaram elevação do nível durante este período em que os dados foram coletados com intervalos de tempo maior. 
Análise da Flutuação do Nível D”água para Estimativa de Recarga Subterrânea da Bacia Representativa do Rio Gramame no Nordeste Brasileiro

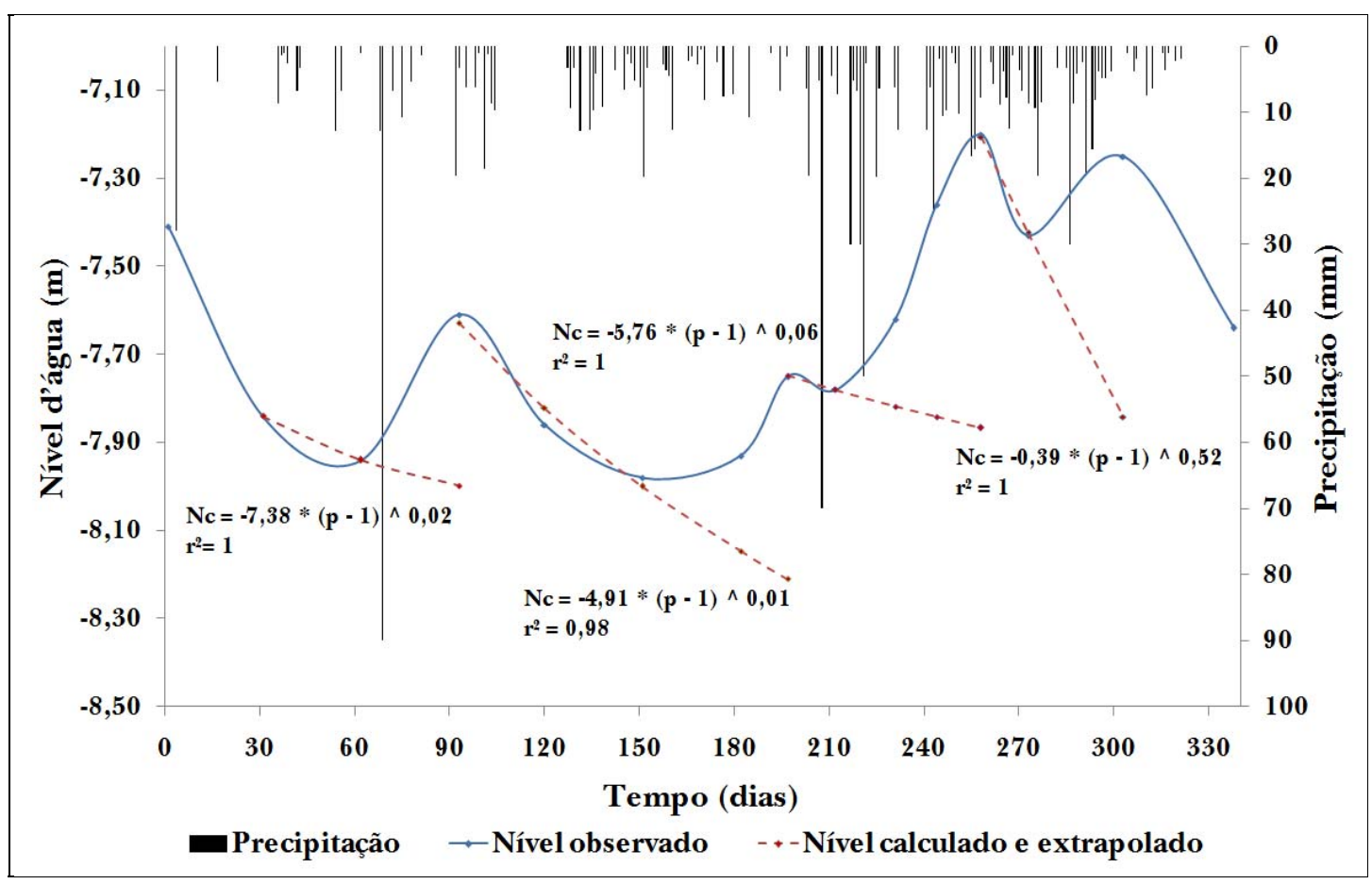

Figura 11 - Nível observado e curvas de recessão extrapoladas para o poço 25

Tabela 1 - Recarga direta por poço da BRG durante o ano hidrológico 2009/2010

\begin{tabular}{lcccccc}
\hline Poço & $\begin{array}{c}\text { Estação } \\
\text { pluv. }\end{array}$ & $\begin{array}{c}\text { Prec. } \\
(\mathbf{m m})\end{array}$ & $\begin{array}{c}\text { Espessura média } \\
\text { da camada não } \\
\text { saturada } \\
(\mathbf{m})\end{array}$ & $\begin{array}{c}\sum \Delta \mathbf{h} \\
\mathbf{( m m})\end{array}$ & $\begin{array}{c}\text { Recarga } \\
(\mathbf{m m})\end{array}$ & $\begin{array}{c}\text { Recarga } \\
\mathbf{( \% )}\end{array}$ \\
\hline P5 & EP2 & 967 & 9,75 & 565,0 & 39,6 & 4,1 \\
\hline P6 & EP2 & 967 & 7,39 & 205,9 & 14,4 & 1,5 \\
\hline P8 & EP2 & 967 & 4,96 & 1796,3 & 125,7 & 13,0 \\
\hline P9 & EP4 & 944 & 9,04 & 238,9 & 16,7 & 1,8 \\
\hline P10 & EP4 & 944 & 6,86 & 1727,9 & 121,0 & 12,8 \\
\hline P11 & EP8 & 1177 & 5,23 & 1651,8 & 115,6 & 9,8 \\
\hline P12 & EP8 & 1177 & 4,16 & 2720,8 & 190,5 & 16,2 \\
\hline P13 & EP8 & 1177 & 4,27 & 198,6 & 13,9 & 1,2 \\
\hline P14 & EP5 & 830 & 2,06 & 595,3 & 41,7 & 5,0 \\
\hline P15 & EP5 & 830 & 5,63 & 464,5 & 32,5 & 3,9 \\
\hline P16 & EP3 & 1195 & 6,95 & 312,2 & 21,9 & 1,8 \\
\hline P17 & EP1 & 1128 & 7,16 & 502,4 & 35,2 & 3,1 \\
\hline P18 & EP1 & 1128 & 8,62 & 2280,7 & 159,6 & 14,1 \\
\hline P19 & EP3 & 1195 & 1,93 & 1319,1 & 92,3 & 7,7 \\
\hline P20 & EP1 & 1128 & 5,70 & 960,7 & 67,2 & 6,0 \\
\hline P21 & EP1 & 1128 & 1,88 & 1256,2 & 87,9 & 7,8 \\
\hline P24 & EP1 & 1128 & 12,86 & 405,1 & 28,4 & 2,5 \\
\hline P25 & EP1 & 1128 & 7,64 & 2107,4 & 147,5 & 13,1 \\
\hline P27 & EP1 & 1128 & 14,32 & 718,2 & 50,3 & 4,5 \\
\hline
\end{tabular}


Tabela 2 - Recarga direta mensal (mm) do poço 12

\begin{tabular}{cccc}
\hline Mês & $\begin{array}{c}\text { Prec. } \\
(\mathbf{m m})\end{array}$ & $\begin{array}{c}\mathbf{\Delta h} \\
(\mathbf{m m})\end{array}$ & $\begin{array}{c}\text { Recarga } \\
(\mathbf{m m})\end{array}$ \\
\hline Novembro & 34 & 0 & 0 \\
\hline Dezembro & 31 & 0 & 0 \\
\hline Janeiro & 171 & 0 & 0 \\
\hline Fevereiro & 71 & 311,0 & 21,8 \\
\hline Março & 54 & 0 & 0 \\
\hline Abril & 138 & 0 & 0 \\
\hline Maio & 64 & 314,3 & 22 \\
\hline Junho & 241 & 683,8 & 47,9 \\
\hline Julho & 141 & 934,0 & 65,4 \\
\hline Agosto & 155 & 477,5 & 33,4 \\
\hline Setembro & 50 & 0 & 0 \\
\hline Outubro & 20 & 0 & 0 \\
\hline Total & 1177 & 2720,8 & 190,5 \\
\hline
\end{tabular}

As menores taxas de recarga foram registradas nos poços $6,9,13,16$ e 24, todos com menos de $20 \mathrm{~mm}$ durante o ano hidrológico pesquisado. Dois deles, os poços 13 e 16, possuem uma camada não saturada média do solo menor do que $7 \mathrm{~m}$ e precipitação acima de $1000 \mathrm{~mm} /$ ano, e conseqüentemente deveriam ter maiores taxas de recarga. O poço 13, enquadrado nas variações do Tipo I, não obteve uma taxa de recarga maior porque suas constantes oscilações foram mínimas durante o ano inteiro, muito provavelmente pela sua proximidade com o rio, onde as águas subterrâneas deveriam estar interagindo e abastecendo o curso d'água superficial. O caso do poço 16 deve estar relacionado às propriedades do solo, já que ele localiza-se nas proximidades de uma área urbanizada, e juntamente com o poço 17, que está muito próximo a ele, foi classificado com sendo de variação do Tipo II. Os outros 3 poços que obtiveram baixas taxas de recarga possuem camadas não saturada do solo mais espessas, o que justifica este comportamento.

Os poços com variação do Tipo I, cuja espessura da camada não saturada é mais delgada, obtiveram taxa de recarga, em sua maioria, superior a $5 \%$ da precipitação, como mostra a Figura 12. Enquanto que os poços com variação do Tipo II, com camada não saturada mais espessa, não ultrapassaram os 5\% de recarga em relação à precipitação.

O valor anual da recarga direta da BRG, obtida através da média aritmética de todos os poços, foi de 73,8 $\mathrm{mm}$ para o período de novembro de 2009 a outubro de 2010, o que representa 7,2\% da precipitação média anual na área de estudo, que foi 1026 $\mathrm{mm}$. O valor encontrado foi abaixo do esperado para uma região úmida, provavelmente devido ao baixo índice pluviométrico durante o ano hidrológico da pesquisa, que foi $42 \%$ menor do que a média anual da bacia. O mapa de recarga anual da BRG (Figura 13), elaborado através da interpolação dos valores obtidos e utilizando o método do inverso da distância ao quadrado, mostra que as maiores taxas foram na parte central da bacia.

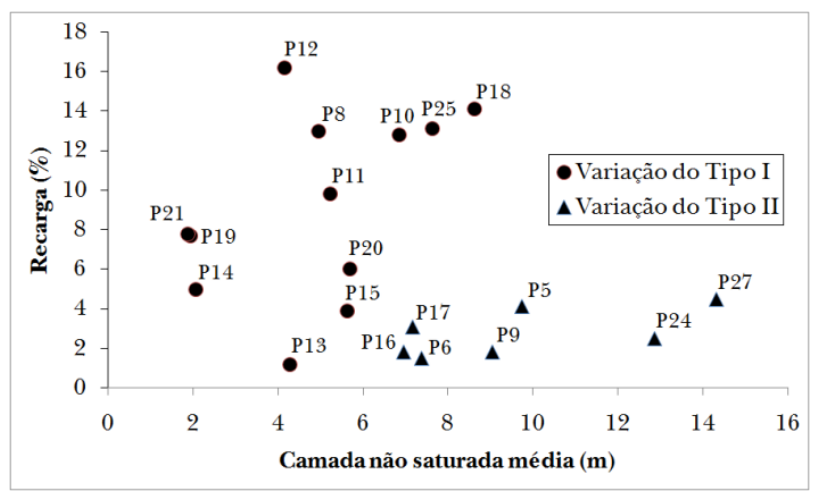

Figura 12 - Taxa de recarga versus camada não saturada do solo dos poços

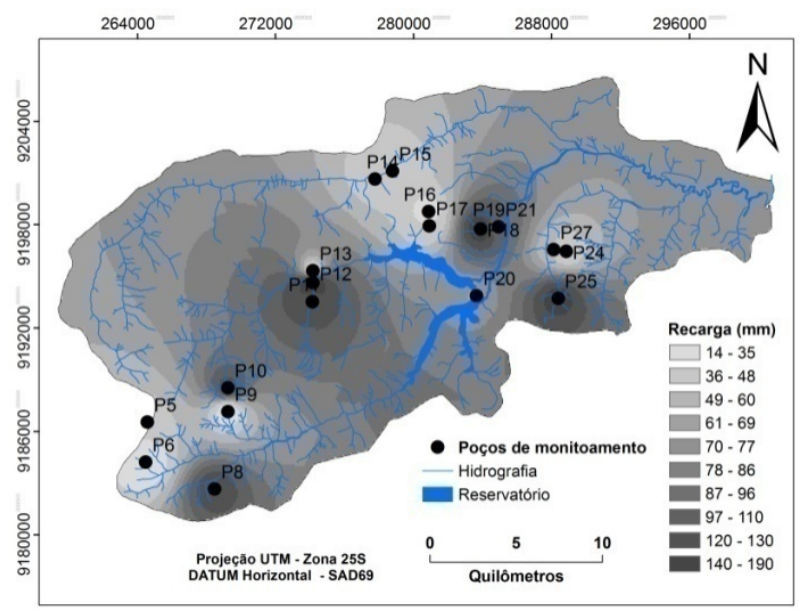

Figura 13 - Mapa de recarga da BRG para o ano hidrológico estudado

\section{Variação do Armazenamento Subterrâneo}

A variação do armazenamento subterrâneo foi negativa em quase todos os poços, o que indica que o volume de água no aqüífero livre diminuiu no período estudado. A exceção foi do poço 19, que possui uma camada vadosa média pouco espessa e o índice pluviométrico foi o mais elevado. A Tabela 3 apresenta os valores obtidos para cada poço analisa- 
do. Observa-se, ainda de acordo com a Tabela 3, que os maiores valores negativos do armazenamento subterrâneo foram dos poços dos Tipos II e III. A variação média anual do armazenamento subterrâneo foi de $-105,9 \mathrm{~mm}$ para a BRG, o que pode provocar a secagem de alguns poços durante o próximo período de estiagem, já que a maioria deles é rasa.

Tabela 3 - Variação do armazenamento $(\mathrm{mm})$ por poço da BRG durante o ano hidrológico 2009/2010

\begin{tabular}{|c|c|c|c|}
\hline Poço & $\begin{array}{c}\Delta \mathbf{h} \\
(\mathbf{m m})\end{array}$ & $\begin{array}{c}\Delta S \\
(\mathbf{m m})\end{array}$ & $\begin{array}{l}\text { Tipo de } \\
\text { variação } \\
\text { do nível }\end{array}$ \\
\hline $\mathrm{P} 1$ & $-517,8$ & $-68,6$ & II \\
\hline $\mathrm{P} 4$ & $-1794,3$ & $-169,4$ & III \\
\hline $\mathrm{P} 5$ & $-1042,8$ & -160 & II \\
\hline $\mathrm{P} 6$ & $-772,3$ & -76 & II \\
\hline $\mathrm{P} 7$ & $-1835,5$ & -281 & III \\
\hline P8 & $-539,4$ & -125 & $\mathrm{I}$ \\
\hline P9 & $-970,9$ & -120 & II \\
\hline P10 & $-683,2$ & -146 & I \\
\hline P11 & $-564,7$ & -98 & $\mathrm{I}$ \\
\hline $\mathrm{P} 12$ & $-439,2$ & -46 & $\mathrm{I}$ \\
\hline P13 & $-438,6$ & -2 & I \\
\hline $\mathrm{P} 14$ & $-217,9$ & -4 & $\mathrm{I}$ \\
\hline $\mathrm{P} 15$ & $-614,0$ & -85 & $\mathrm{I}$ \\
\hline P16 & $-806,3$ & -236 & II \\
\hline $\mathrm{P} 17$ & $-807,8$ & -208 & II \\
\hline P18 & $-863,9$ & -43 & $\mathrm{I}$ \\
\hline P19 & 207,3 & 40 & I \\
\hline $\mathrm{P} 20$ & $-561,7$ & -26 & $\mathrm{I}$ \\
\hline $\mathrm{P} 21$ & $-193,1$ & -3 & $\mathrm{I}$ \\
\hline $\mathrm{P} 23$ & $-3015,5$ & -205 & III \\
\hline $\mathrm{P} 24$ & $-1376,0$ & -263 & II \\
\hline $\mathrm{P} 25$ & $-756,6$ & -16 & $\mathrm{I}$ \\
\hline $\mathrm{P} 27$ & $-1482,4$ & -231 & II \\
\hline
\end{tabular}

\section{CONCLUSÕES E RECOMENDAÇÕES}

No presente trabalho foi determinada a recarga direta do aqüífero livre da BRG, utilizando o método WTF (Water Table Fluctuation). Para a aplicação do método foi necessário o monitoramento dos níveis de poços distribuídos pela bacia. Durante este monitoramento foram detectados três grupos de poços, que apresentaram comportamentos distintos da flutuação dos níveis estático, marcados pelo constante rebaixamento, pelas respostas lentas aos eventos de precipitação e pelas variações maiores. Investigações buscaram entender estes diferentes compor- tamentos, sendo a precipitação, a espessura da camada não saturada do solo e a elevação do terreno os fatores que exerceram maiores influências no comportamento do aqüífero. A freqüência do monitoramento adotada nesta pesquisa foi satisfatória para acompanhar as mudanças na elevação do nível estático do aqüífero provocada pelas precipitações, principalmente quando as campanhas foram quinzenais, reforçando o que foi sugerido por Wendland et al. (2007).

A recarga direta, calculada pelo método WTF para o ano hidrológico do monitoramento (2009/2010), foi de 73,8 mm, o que representa 7,2\% da precipitação. Este baixo valor refletiu na variação do armazenamento subterrâneo, que foi negativo para o período de estudo, cujo valor foi de $-105,9$ $\mathrm{mm}$. Estes baixos valores foram decorrentes do baixo índice pluviométrico anual (1026 mm) na região, para o período estudado. Os resultados obtidos permitem fazer algumas recomendações para os trabalhos subseqüentes e para um melhor gerenciamento dos recursos hídricos subterrâneos da BRG, são elas:

1. Uma maior quantidade de poços a serem monitorados para melhor representar a distribuição espacial dos valores de recarga obtidos pelo método WTF. O mais recomendado seria a perfuração de piezômetros em locais estratégicos da bacia, para que não haja nenhuma interferência que possa comprometer a qualidade dos dados, como aconteceu nos poços em que houve bombeamento.

2. A instalação de sondas para a medição automática do nível estático diariamente, a fim de detectar as mudanças num intervalo de tempo menor do que quinzenal, principalmente nos poços que possuem uma zona nãosaturada delgada.

3. A determinação do coeficiente de rendimento específico para cada poço monitorado, através da coleta de amostras indeformadas do solo nas profundidades que compreendem as faixas de variação do nível do aqüífero freático, para que os resultados da recarga pontual sejam mais exatos. Uma vez que o valor apresentado neste trabalho corresponde a uma média do coeficiente de rendimento específico, obtido através da literatura, subentendendo, assim, um meio homogêneo.

4. A aplicação de outras técnicas de estimativa de recarga, concomitantemente ao WTF, para que os resultados possam ser comparados. 


\section{AGRADECIMENTOS}

Os autores agradecem à CAPES pela concessão da bolsa de estudos e à FINEP pelo suporte financeiro ao projeto BEER (Bacias Experimentais e Representativas do Semi-Árido).

\section{REFERÊNGIAS}

ALHEIROS, M. M.; LIMA FILHO, M. F.; MONTEIRO, F. A. J.; OLIVEIRA FILHO, J. S. (1988). Sistemas deposicionais na Formação Barreiras no Nordeste Oriental. In: Congresso Brasileiro de Geologia, v.2, p.753-760.

BANERJEE, P.; PRASAD, R. K.; SINGH, V. S. (2009). Forecasting of groundwater level in hard rock region using artificial neural network. Environ. Geol. v.58, p.12391246.

BARBOSA, J. A.; NEUMANN, V. H.; LIMA FILHO, M. F.; SOUZA, E. M. de.; MORAES, M. A. de. (2007). Estratigrafia da Faixa Costeira Recife-Natal (Bacia da Paraíba e Plataforma de Natal), NE Brasil. Estudos Geológicos, v.17, p.3-30.

BARRETO, C. E. A. G. (2006). Balanço Hídrico em zona de afloramento do Sistema Aqǘfero Guarani a partir de monitoramento hidrogeológico em bacia representativa. Dissertação (Mestrado em Hidráulica e Saneamento) - Escola de Engenharia de São Carlos, Universidade de São Paulo, São Carlos, 249p.

BORBA, A. L. S.; COSTA FILHO, W. D.; MASCARENHAS, J. C. (2010). Configuração geométrica dos Aqüiferos da Região Metropolitana do Recife. In: Anais do XVI Congresso Brasileiro de Águas Subterrâneas e XVII Encontro Nacional de Perfuradores de Poços, São Luís - MA, p.1-14.

CARNIER NETO, D.; HUNG KIANG, C. (2008). Aplicação do método de flutuação de nível da água para a estimativa de recarga - Exemplo do Aqüifero Rio Claro. Águas Subterrâneas, v.22, p.39-48.

CARRERA-HERNÁNDEZ, J. J.; GASKIN, S. J. (2007). The Basin of Mexico aquifer system: regional groundwater level dynamics and database development. Hydrogeology Journal, v.15, p.1577-1590.

COELHO, V. H. R. (2011). Monitoramento e análise da variação do nível d'água para estimativa da recarga do aqüifero livre da bacia do rio Gramame - PB. Dissertação (Mestrado em Engenharia Urbana e Ambiental) - Centro de Tecnologia, Universidade Federal da Paraíba, João Pessoa, 146p.

COES, A. L.; SPRUILL, T. B.; THOMASSON, M. J. (2007). Multiple-method estimation of recharge rates at di- verse locations in the North Carolina Coastal Plain, USA. Hydrogeology Journal, v.15, p.773-788.

COSTA, W. D.; ALBUQUERQUE, J. P. T.; CASTELO BRANCO, R. L.; MARANHÃO, C. M. L.; GOLDFABER, M. (2007). Estudo de caracterização e verificação da disponibilidade hídrica da vertente litorânea do estado da Paraíba. Estudos Hidrogeológicos. Relatório Final. Tomo I - Texto. Ministério da Integração Nacional, $125 p$.

DELIN, G. N.; HEALY, R. W.; LORENZ, D. L.; NIMMO, J. R. (2006). Comparison of local-to regional-scale estimates of ground-water recharge in Minnesota, USA. Journal of Hydrology, v.334, p.231-249.

FEITOSA, E. C.; FEITOSA, F. A. C. (2008). Metodologia básica de pesquisa de água subterrânea. In: Hidrogeologia: conceitos e aplicações. Org. por Feitosa, F. A. C.; Manoel Filho, J.; Feitosa, E. C.; Demetrio, J. G. A., CPRM: LABHID, Rio de Janeiro - RJ, p.179-206.

FURRIER, M.; ARAÚJO, M. E. de.; MENESES, L. F. (2006). Geomorfologia e Tectônica da Formação Barreiras no Estado da Paraíba. Geologia USP Série Científica, v.6, p.61-70.

GOMES, L. H. (2008). Determinação da recarga profunda na Bacia-Piloto do Ribeirão da Onça em zona de afloramento do sistema Aqüifero Guarani a partir de balanço hídrico em zona saturada. Dissertação (Mestrado em Hidráulica e Saneamento) - Escola de Engenharia de São Carlos, Universidade de São Paulo, São Carlos, 167p.

HEALY, R. W.; COOK, P. G. (2002). Using groundwater levels to estimate recharge. Hydrogeology Journal, v.10, p.91-109.

JOHNSON, A. I. (1967). Specific yield - compilation of specific yields for various materials. US Geological Survey Water Supply. Paper 1662-D, 74p.

LERNER, D. N.; ISSAR, A. S.; SIMMERS I. (1990). Groundwater Recharge: a guide to understanding and estimating natural recharge. International Contributions to Hydrogeology, v.8, 345p.

LUCENA, L. R. F.; ROSA FILHO, E. F.; HINDI, E. C. (2006). O controle estrutural no Aqüífero Barreiras - Área da bacia do rio Pirangi-RN. Águas Subterrâneas, v.20, p.83-98.

MARÉCHAL, J. C.; DEWANDEL, B.; AHMED, S.; GALEAZZI, L.; ZAIDI, F. K. (2006). Combined estimation of specific yield and natural recharge in a semi-arid groundwater basin with irrigated agriculture. Journal of Hydrology, v.329, p.281-293.

MAZIEIRO, T. A. (2005). Monitoramento de água subterrânea em área urbana: aspectos quantitativos. Dissertação (Mestrado em Hidráulica e Saneamento) - Escola de Engenharia de São Carlos, Universidade de São Paulo, São Carlos. 
Análise da Flutuação do Nível D”água para Estimativa de Recarga Subterrânea da Bacia Representativa do

Rio Gramame no Nordeste Brasileiro

MAZIERO, T. A.; WENDLAND, E. (2008). Variabilidade espacial da recarga em área urbana. Revista Brasileira de Recursos Hídricos, v.13, n.3, p.35-46.

MELO, J. G.; MORAES, S. D.; VASCONCELOS, M. B. (2010). Potencialidade e qualidade das águas do Aqüífero Barreiras na região da Lagoa de Extremoz, RN. Revista de Geologia, v.22, p.137-149.

MENTE, A. (2008). A água subterrânea no Brasil. In: Hidrogeologia: conceitos e aplicações. Org. por Feitosa, F. A. C.; Manoel Filho, J.; Feitosa, E. C.; Demetrio, J. G. A., CPRM: LABHID, Rio de Janeiro - RJ, p.31-48.

MOON, S.; WOO, N. C.; KWANG, G. L. (2004). Statistical analysis of hydrographs and water-table fluctuation to estimate groundwater recharge. Journal of Hydrology, v.292, p.198-209.

PDRH. (2000). Plano Diretor de Recursos Hídricos da Bacia do Rio Gramame. SEMARH/SCIENTEC.

RABELO, J. L. (2006). Estudo da recarga do Aqüífero Guarani no sistema Jacaré-Tietê. Tese (Doutorado em Hidráulica e Saneamento) - Escola de Engenharia de São Carlos, Universidade de São Paulo, São Carlos, 200p.

SANFORD, W. (2002). Recharge and groundwater: an overview. Hydrogeology Journal, v.10, p.110-120.

SCANLON, B. R.; HEALY, R. W.; COOK, P. G. (2002). Choosing appropriate techniques for quantifying groundwater recharge. Hydrogeology Journal, v.10, p.18-39.

SHARDA, V. N.; KUROTHE, R. S.; SENA, D. R.; PANDE, V. C.; TIWARI, S. P. (2006). Estimation of groundwater recharge from water storage structures in a semi-arid climate of India. Journal of Hydrology, v.329, p.224243.

SIBANDA, T.; NONNER, J. C.; UHLENBROOK, S. (2009). Comparison of groundwater recharge estimation methods for the semi-arid Nyamandhlovu area, Zimbabwe. Hydrogeology Journal, v.17, p.1427-1441.

SILVA, S. R.; MONTEIRO, A. B.; CABRAL, J. J. S. P.; BORBA, A. L. S.; FREIRE, P. K. C.; COSTA, W. D.; BARBO$\mathrm{SA}, \mathrm{G}$. F. (2008). A gestão de águas subterrâneas no Aqüífero Barreiras - Jordão, Jardim Jordão e Ibiura Recife - Pernambuco. Anais do XV Congresso Brasileiro de Águas Subterrâneas, Natal - RN.

VRIES, J. J.; SIMMERS, I. (2002). Groundwater recharge: an overview of processes and challenges. Hydrogeology Journal, v.10, p.5-17.

WAHNFRIED, I.; HIRATA, R. (2005). Comparação de métodos de estimativa de recarga de aqüíferos em uma planície aluvionar na bacia hidrográfica do Alto Tietê (São Paulo). Revista Brasileira de Recursos Hídricos, v.10, n.2, p.15-25.

WENDLAND, E.; BARRETO, C.; GOMES, L. H. (2007). Water balance in the Guarani Aquifer outcrop zone based on hydrogeologic monitoring. Journal of Hydrology, v.342, p.261-269.
WHO - World Health Organization. (2006). Protecting groundwater for health - Managing the quality of drinkingwater sources. 155p.

ZHOU, Y. (1996). Sampling frequency for monitoring the actual state of groundwater systems. Journal of Hydrology, v.180, p.301-318.

\section{Water Level Fluctuation Analysis to Estimate Groundwater Recharge of the Representative Gramame Watershed in the Brazilian Northeast}

\section{ABSTRACT}

It is necessary to monitor and understand the aquifer recharge rate for efficient and sustainable management of groundwater. This paper present the results of the direct recharge rate of the representative Gramame watershed (BRG) free aquifer, using the water table fluctuation method (WTF). For this, the groundwater was monitored quantitatively using existing wells in the region and processing rainfall data in the watershed. Three different behaviors were detected in the fluctuations of well levels, influenced by rainfall distribution, thickness of unsaturated soil and topography. The direct recharge calculated for the BRG during the hydrological monitoring year (2009/2010) was $73.8 \mathrm{~mm}$, representing $7.2 \%$ of average rainfall $(1026 \mathrm{~mm})$ in the region. These values were lower than expected for a humid region, probably because of low rainfall during the research, which was approximately $42 \%$ less than the annual average in the watershed. The low rainfall also influenced the negative subsurface storage $(\Delta S),-105.9 \mathrm{~mm}$. It is recommended that the aquifer be monitored systematically for a longer time to provide subsidies for groundwater use in the $B R G$.

Key-words: groundwater, monitoring, direct recharge, WTF method. 